\title{
Callus Induction and Organogenesis in Soybean [Glycine max (L.) Merr.] cv. Pyramid from Mature Cotyledons and Embryos
}

\author{
Ebony Y. Joyner, LaShonda S. Boykin and Muhammad A. Lodhi* \\ Cellular and Molecular Biotechnology Laboratory, Department of Biological Sciences, Fayetteville State University, \\ 1200 Murchison Road, Fayetteville, NC 28301, USA
}

\begin{abstract}
Soybean is one of the most important legumes of the world. Soybean plants are affected by several biotic and abiotic factors as well as insect pests and diseases which lower the quality and production of the crop. In order to overcome these biotic and abiotic challenges, a systematic crop improvement plan has to be followed in order to enhance crop production which involves the use of new technologies and developing new cultivars with desirable qualities. With the completion of the soybean genome sequencing project, it is anticipated that access to desirable gene sequences will advance soybean improvement efforts. Two general approaches for in vitro plant regeneration are used; somatic embryogenesis from immature embryos and organogenesis from mature parts of the plant and seeds. In vitro regeneration in soybean depends upon several physical, biochemical and genetic factors. Different genotypes respond differently to the method of regeneration used. Pyramid soybean is used in several breeding and mapping projects but does not have a regeneration procedure worked out. The goal of our project was to develop an in vitro regeneration procedure for soybean cv. Pyramid that would be amenable to genetic manipulations. We excised cotyledons and embryos from germinating seeds and induced callus with various concentrations of 2,4-D and NAA, used alone or in combination. 2,4-D at 3-21 $\mu \mathrm{M}$ concentrations in the culture media produced $100 \%$ callus induction from cotyledons. After callus formation we transferred them to BAP and Kinetin containing culture media and obtained roots and shoots; $5 \mu \mathrm{M}$ BAP was the most effective for that purpose. Fully developed plants were transplanted to the pots in less than three months where they produced healthy seeds in July.
\end{abstract}

Keywords: Glycine max, Pyramid, cotyledons, embryos, organogenesis, callus induction, 2,4-D, BAP.

\section{INTRODUCTION}

Soybean, Glycine max (L.) Merr., is an important grain legume that is not only a valuable oil crop but also used as feed for livestock and aquaculture. Soybean is a rich source of dietary proteins and used as raw and processed food as well as in drinks. Wide cultivation of soybean in all climatic zones of the world makes it one of the most valuable farm products. In 2009, world-wide production was 210.9 million metric tons and the contribution of USA in that yield was $38 \%$ [1]. It is projected that at the current yield level, world soybean production will rise to 311.1 million metric tons by 2020 [2]. With the rise in world population, food production has to be increased. Crops like soybean, corn, rice and wheat will play a significant role along with non-traditional food sources. In order to boost the production of crops, including soybean, a sustainable crop improvement is needed to overcome the challenges of biotic and abiotic stresses, such as salt, drought, water-logging, high and low temperatures, diseases, weeds and insect pests. About $37 \%$ of the crop yield is lost to weeds, pests and diseases [3]. A tremendous amount of work is needed to improve soybean crop against internal and external stresses. Traditional methods of

*Address correspondence to this author at the Cellular and Molecular Biotechnology Laboratory, Department of Biological Sciences, Fayetteville State University, 1200 Murchison Road, Fayetteville, NC 28301, USA; Tel: 910-672-1658; Fax: 910-672-1159; E-mail: mlodhi@uncfsu.edu soybean improvement are very lengthy and less effective against multiple stress factors. In vitro and molecular methods are being devised and used to enhance crop improvement process by using plant tissue culture, recombinant technology and marker-assisted selection [3].

Soybean genome sequencing was completed in 2008 [4, $5]$ and is only the third plant genome to be sequenced. The entire sequence is accessible through SoyBase database [24]. Genome sequence provides enormous amount of genetic information and is bound to help identify genes of desirable traits that are related to insect pest and disease resistance, yield and water stresses. In addition genome sequence can reveal components of the metabolic pathways responsible for quality of proteins and fatty acids that can be utilized in the improvement of soybean cultivars.

Improvement of crops through plant tissue culture can be accomplished by growing plants in a laboratory through callus initiation and regeneration of shoots and roots or regeneration of multiple plants directly from small pieces of leaves, shoots, seeds, embryos or cotyledons. Once callus is formed, it can be manipulated with the addition of cloned gene products or interference RNA (RNAi) by genetic transformation mediated by indirect methods such as Agrobacterium tumefaciens [3, 6, 7] or direct methods such as particle bombardment, electroporation and silicon carbide particles [8]. Callus is advantageous for indirect methods due to efficient transformation, selection and regeneration of the cells [9]. 
Numerous methods have been introduced for soybean regeneration over the last several decades that are based on somatic embryogenesis or direct organogenesis [8, 10-16]. Several factors affect the regeneration process that include; selection of the explants, media composition, environmental conditions and the genotype of the soybean cultivar. Genotype plays a critical role in soybean regeneration through tissue culture along with the choice of different growth hormones [17-19]. Several soybean cultivars are used in our department for genetic mapping by faculty and graduate students in collaboration with outside faculty in various projects. To our knowledge no regeneration method is currently available for Pyramid. We aimed at developing a regeneration method for several cultivars including Pyramid. Pyramid is an important soybean cultivar and has been used in several breeding and mapping efforts aimed at disease resistance [20]. The protocol developed for Pyramid will be used for genetic transformation with novel genes identified by the genome sequence and RNAi as well as for crop improvement by marker-assisted selection.

\section{MATERIALS AND METHODS}

Soybean seeds were provided by Dr. Randall Nelson, National Soybean Research Center, USDA-ARS, Urbana, IL. The seeds were stored in a desiccator at room temperature till used.

\section{Seed Sterilization}

Vapor-phase seed sterilization method of Maude Hinchee (unpublished) was used to decontaminate seeds. Seeds were added to a $100 \mathrm{~cm}^{2}$ glass Petri plate and placed inside a desiccator along with a beaker containing $97 \mathrm{ml}$ commercial Chlorox ${ }^{\circledR}$. The desiccator was then placed under a fume hood and $3 \mathrm{ml}$ concentrated hydrochloric acid was added to Chlorox ${ }^{\circledR}$ and immediately the lid was placed on the desiccator. Seeds were removed from the desiccator after 5-24 hrs. In the Petri plate, $10-15 \mathrm{ml}$ sterile deionized water was added to hydrate the cotyledons and embryos for 20-24 hrs.

\section{Media Preparation}

Culture media was prepared using Murashige and Skoog [21] salts (M5524; Sigma-Aldrich) added with MS micronutrients (Carolina Biologicals), vitamins (M7150; SigmaAldrich), casein hydrolysate (82514; Fluka), 3\% sucrose (S0389; Sigma-Aldrich) and $0.8 \%$ agar (Carolina Biologicals). Media was adjusted to $\mathrm{pH}$ 5.6-5.7, autoclaved at 121 ${ }^{\circ} \mathrm{C}$ and 16 pounds/square inch for 15 minutes and dispensed in the baby food jars when the temperature of the media dropped to $50-60{ }^{\circ} \mathrm{C}$. For initiation of callus MS media was modified with indole-3-acetic acid [(IAA), (I2886; SigmaAldrich)] at 0, 3, 9, 15 and $21 \mu \mathrm{M} ; 2$,4- dichlorophenoxy acetic acid [(2,4-D), (D7299; Sigma-Aldrich)] at 0, 3, 9, 15 and $21 \mu \mathrm{M} ; \alpha$-naphthalene acetic acid [(NAA), (N0640; Sigma-Aldrich)] at $0,3,9,15$ and $21 \mu \mathrm{M}$ or a combination of 2,4-D and NAA at $3+3,9+9$ and $15+15 \mu \mathrm{M}$ each. Shoot initiation from callus was carried out in MS media modified with 6-benzyl aminopurine [(BAP), (B3408; SigmaAldrich)] at 0, 5, 10 and $15 \mu \mathrm{M}$; Kinetin [(Kin), (K0753, Sigma-Aldrich)] at $0,5,10$ and $15 \mu \mathrm{M}$, or a combination of
BAP and Kinetin at 5+5, 10+10 and $15+15 \mu \mathrm{M}$ each. For each concentration one jar were prepared.

\section{Explant Excision and Callus Initiation}

Membranous seed coats of the hydrated seeds were removed with the help of a scalpel. Seeds were cut longitudinally in order to open the two cotyledons and expose the embryos. Full embryos were taken out gently with the help of forceps and transferred to callus media. Five embryos, excised out of five seeds, were cultured in one jar and ten cotyledons from the same seeds were added to one jar with each concentration of callus media containing NAA, 2,4-D and their combinations. Media jars were incubated in Biotronette Mark III Environmental Chamber incubator (Bio-Line) under $16 \mathrm{hr}$ photoperiod maintained with fluorescent and incandescent lights at room temperature. Explants were kept in the callus media for 3-4 weeks. Observations were recorded weekly until week 6 and no media was changed during that time.

\section{Shoot and Root Formation}

Once callus was formed in the jars with cotyledons and embryos, it was transferred to shoot media containing BAP, Kinetin or combinations of the both. Environmental conditions for shoot/root formation were the same as for callus induction. No special media modifications were done to induce roots. Rooted shoots were transplanted in vermiculite in $100 \%$ relative humidity for $24-48 \mathrm{hrs}$ and then to $40 \mathrm{~cm}$ pots with Miracle-Gro Potting Mix in the greenhouse and later on the pots were moved to outside of the greenhouse.

\section{RESULTS AND DISCUSSION}

Abundant amounts of calli were obtained either from the cotyledons in the media modified with $2,4-\mathrm{D}$ or from cotyledons with 2,4-D and NAA combined. 2,4-D was effective in initiating callus in the two types of explants used in this experiment at all concentrations between 3-21 $\mu \mathrm{M}$. 2,4-D has been successfully used by many other researchers to regenerate soybean plants [16, 19, 22], although concentration varied widely. For example, in our experiment both the highest $(21 \mu \mathrm{M})$ and the lowest $(3 \mu \mathrm{M})$ concentrations of 2,4-D used produced callus. Loganathan et al. [16] used 164.8 $\mu \mathrm{M}$ 2,4-D and Kumari et al. [22] used $180.8 \mu \mathrm{M}$ to produce callus. This disparity in the callus induction at significantly different concentrations, indicates genotype specific responses. In our experiment, higher concentration of 2,4-D alone or in combination with NAA, e.g., $15 \mu \mathrm{M}$, initiated callus faster (within 2 weeks) than lower concentrations $(3 \mu \mathrm{M})$ and subsequent callus growth was also much faster than the callus produced at lower concentrations (Fig. 1A). A higher percentage of cotyledons produced callus than did embryos (Table 1). NAA alone promoted shoot and root formation. Similar results were produced when cotyledons were cultured in media containing IAA (data not shown). Selective response of Pyramid cotyledons and embryos to callus formation with different growth regulators may be due to the genotypic difference of soybean in different cultivars. We have observed such genotype specific responses in other cultivars such as Blackhawk, Forrest and Douglas (unpublished data). Hiraga et al. [23] found that somatic embryo- 

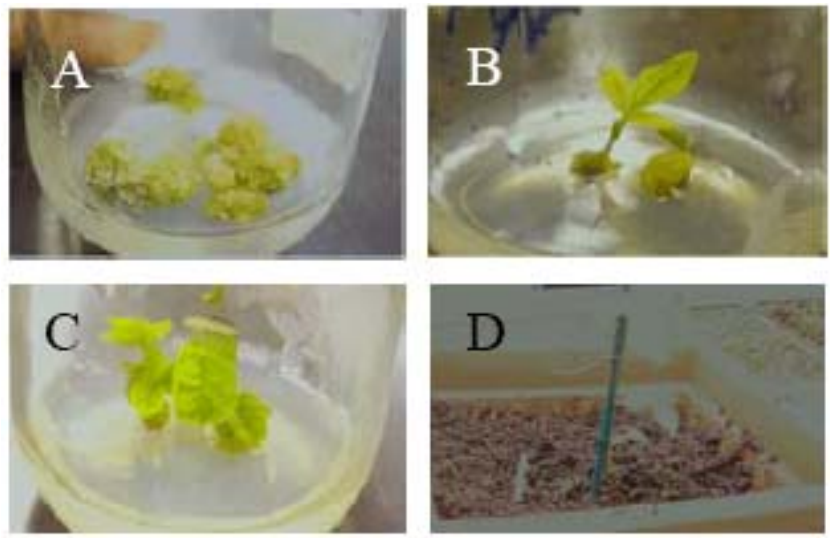

Fig. (1). Soybean plant regeneration from excised cotyledons. Cotyledons were cultured in various concentrations of 2,4-D, NAA and combinations of both growth regulators to induce callus. Once callus was produced, it was transferred to new culture media containing various concentrations of BAP, Kinetin and combinations of both to produce shoots. Roots germinated on the shoots without the change of media in BAP and Kinetin media. A) Cotyledons produced profuse callus within 2-3 weeks in $3 \mu \mathrm{M}$ 2,4-D. B) Shoot formation from callus in media containing $10 \mu \mathrm{M}$ BAP. C) Roots produced in BAP and Kinetin media. D) Rooted shoots were transplanted into vermiculite containing pots under $100 \%$ relative humidity for 24 hours and then to the greenhouse in pots.

genesis and plant regeneration of several Japanese cultivars was superior or comparable to the North American cultivar 'Jack'. Sairam et al. [19] found significant differences in plant regeneration in various soybean cultivars through organogenesis.

Calli from most of the cotyledons and some of the embryos (from culture media with $3,9,15$ and $21 \mu \mathrm{M}$ of $2,4-\mathrm{D}$ or in combination with NAA) were cultured in the media modified with BAP, Kinetin and their combinations. Some calli, especially in NAA that also had developed roots and/or shoots was not used for shoot formation. Healthy calli were moved to BAP/Kinetin media within 5-6 weeks of the start of the callus induction. Shoot regeneration was observed in BAP media at 5 and $10 \mu \mathrm{M}$ concentrations or in media with $5+5 \mu \mathrm{M}$ BAP and Kinetin (Fig 1B). Our results for shoot regeneration with 5-10 $\mu \mathrm{M}$ BAP are in agreement with Dan and Reichert [12]; Kumari et al. [19] and Sairam et al. [22]. No shoot formation was observed at higher concentrations than $10 \mu \mathrm{M}$ BAP. Similarly, in culture media with Kinetin no shoot regeneration occurred even though callus turned green and some aggregation of callus was seen in 5, 10 and $15 \mu \mathrm{M}$ Kinetin. Kim et al. [13] found that soybean cultivars 'Pungsannamulkong' and 'Ilpumgeomjeongkong' produced adventitious shoots when BAP was used in the media whereas 'Alchangkong' produced shoot when treated with zeatin and IAA. Response to BAP for shoot regeneration occurred within 4 weeks. In most cases of shoot regeneration, shoots emerged first immediately followed by root formation without any change in the media or environmental conditions (Fig. 1C).

Once the new plantlets grew 1-2 inches in height, they were transplanted to sterile vermiculite and covered with plastic bags to create $100 \%$ relative humidity. After $24 \mathrm{hrs}$ in high relative humidity, the plants were transplanted to $8 \mathrm{~cm}$ pots containing Miracle-Gro Potting Mix and kept inside of the greenhouse for acclimatization (Fig. 1D). During the month of May, plants were moved to $40 \mathrm{~cm}$ pots and placed outside the greenhouse. The entire regeneration procedure, from excision of explants to transplant to $40 \mathrm{~cm}$ pot, took about 12 weeks. Regenerated plants produced vigorous plants and abundant seeds. The procedure is robust and does not need additional time for rooting. We are planning to use this procedure on other cultivars, such as Forrest, Rivers, Hartwig, Blackhawk, Douglas, Essex and their progeny to understand the effect of genotype on regeneration ability. In collaboration with other groups at the University of Illinois and Fayetteville State University we plan to map genes responsible for regeneration ability of the plant. Those genes may be helpful in expediting the molecular breeding and crop improvement procedures.

We have developed a simple, robust and inexpensive procedure to regenerate soybean $\mathrm{cv}$. Pyramid with the use of 2,4-D and BAP. This procedure circumvents the need to use rooting media for the formation of roots on the shoots thus saves time and cost. Soybean plants can be produced within three months in any tissue culture laboratory without the need of any specialized chemicals and equipment.

Table 1. Callus Induction in Cotyledons (C) or Embryos (E) Cultured in Different Concentrations of 2,4-D, NAA and Combinations of 2,4-D and NAA. Each Concentration of the Growth Hormones was Tested with 5 Embryos and 10 Cotyledons Isolated from Pyramid Seeds

\begin{tabular}{|c|c|c|c|c|c|c|c|c|c|c|c|}
\hline & & \multicolumn{2}{|c|}{$\mathbf{0} \mu \mathbf{M}$} & \multicolumn{2}{|c|}{$3 \mu \mathbf{M}$} & \multicolumn{2}{|c|}{$9 \mu \mathrm{M}$} & \multicolumn{2}{|c|}{$15 \mu \mathrm{M}$} & \multicolumn{2}{|c|}{$21 \mu \mathrm{M}$} \\
\hline & & $\mathbf{C}$ & $\mathbf{E}$ & $\mathbf{C}$ & $\mathbf{E}$ & $\mathbf{C}$ & $\mathbf{E}$ & $\mathbf{C}$ & $\mathbf{E}$ & $\mathbf{C}$ & $\mathbf{E}$ \\
\hline $2,4-\mathrm{D}$ & Shoot/root (\%) & 0 & 10 & 0 & 0 & 40 & 0 & 0 & 0 & 60 & dead \\
\hline NAA & Callus (\%) & 0 & 0 & 0 & 0 & 40 & 0 & 0 & 0 & 0 & 0 \\
\hline \multirow{2}{*}{$2,4-\mathrm{D}+\mathrm{NAA}(\mathrm{ea})$} & Callus (\%) & 0 & 0 & 100 & 60 & 100 & 10 & 100 & 0 & 100 & 20 \\
\hline & Shoot/root (\%) & 0 & 0 & 10 & 20 & 0 & 0 & 0 & 0 & 0 & 0 \\
\hline
\end{tabular}




\section{ACKNOWLEDGEMENTS}

The authors are thankful to Professor Randall Nelson, Curator of the USDA Soybean Germplasm Collection, USDA-ARS, Urbana, Illinois for providing seeds for Pyramid soybean. Help of Ms. Pam Ratcliff with the management of the project in the growth chambers and greenhouse is also acknowledged.

\section{REFERENCES}

[1] Soystat - http://soystats.com/2010/page_30.htm Retrieved on August 5, 2010.

[2] Masuda T, Goldsmith PD. World soybean production: Area harvested, yield, and long-term projections. International Food and Agribusiness Management Review 2009; 12: 143-162.

[3] Slater A, Scott NW, Fowler MR. The genetic manipulation of herbicide tolerance. Oxford University Press 2008; pp. 107.

[4] JGI, 2008. DOE JGI Releases Soybean Genome Assembly http://www.jgi.doe.gov/News/news_1_17_08.html.

[5] Schmutz J, Cannon SB, Schlueter J, et al. Genome sequence of the palaeopolyploid soybean. Nature 2010; 463: 178-183.

[6] Subramanian S, Graham MY, Yu O, Graham TL. RNA interference of soybean isoflavone synthase genes leads to silencing in tissues distal to the transformation site and to enhanced susceptibility to Phytophthora sojae. Plant Physiol 2005; 137: 1345-1353.

[7] Kita Y, Nishizawa K, Takahashi M, Kitayama M, Ishimoto M. Genetic improvement and regeneration in soybean and transformation of the improved breeding lines. Plant Cell Rep 2007; 26: 439447.

[8] Finer JF, McMullen D. Transformation of soybean via particle bombardment of embryogenic suspension culture tissue. In Vitro Cell Dev Biol - Plant 1991; 27: 175-182.

[9] Radhakrishnan R, Ranjithakumari BD. Callus induction and plant regeneration of Indian soybean (Glycine $\max$ (L.) Merr. cv. CO3) via half seed explants culture. J Agri Technol 2007; 3: 287-297.

[10] Barwale UB, Kerns HR, Widholm JM. Plant regeneration from callus cultures of several soybean genotypes via embryogenesis and organogenesis. Planta 1986; 167: 473-481.

[11] Christou P, Swain WF, Yang NS, McCabe DE. Inheritance and expression of foreign genes in transgenic soybean plants. Proc Natl Acad Sci USA 1989; 86: 7500-7504.
[12] Dan Y, Reichert NA. Organogenic regeneration of soybean from hypocotyls explants. In Vitro Cell Dev Biol - Plant 1998; 34: 14-21.

[13] Kim YJ, Park TI, Kim HS, Park KH, Chon SU, Yun SJ. Factors affecting organogenesis from mature cotyledon explants and regeneration in soybean. J Plant Biotechnol 2004; 6: 39-43.

[14] Shan Z, Raemakers K, Tzitzikas EN, Ma Z, Visser RGF. Development of a highly efficient, repetitive system of organogenesis in soybean (Glycine max (L.) Merr.). Plant Cell Rep 2005; 24: 507512.

[15] Yang C, Zhao T, Yu D, Gai J. Somatic embryogenesis and plant regeneration in Chinese soybean [Glycine $\max$ (L.) Merr.] impacts of mannitol, abscisic acid and explants age. In Vitro Cell Dev Bio - Plant 2009; 45: 180-188.

[16] Loganathan M, Maruthasalam S, Shiu YL, Lien WC, Hsu WH, Lei $\mathrm{PF}, \mathrm{Yu} \mathrm{CW}$, Lin $\mathrm{CH}$. Regeneration of soybean (Glycine max $\mathrm{L}$. Merrill) through direct somatic embryogenesis from the immature embryonic shoot tip. In Vitro Cell Dev Bio - Plant 2010; 46: 265273.

[17] Bailey MA, Boerma HR, Parrott WA. Genotype effects on proliferative embryogenesis and plant regeneration of soybean. In Vitro Cell Dev Biol - Plant 1993; 29: 102-108.

[18] Simmonds DH, Donaldson PA. Genotype screening for proliferative embryogenesis and biolistic transformation of short-season soybean genotypes. Plant Cell Rep 1999; 19: 485-490.

[19] Sairam RV, Franklin G, Hassel R, et al. A study on the effect of genotypes, plant growth regulators and sugars in promoting plant regeneration via organogenesis from soybean cotyledonary nodal callus. Plant Cell Tissue Organ Cul 2003; 75: 79-85.

[20] Kazi S, Shultz J, Afzal J, Johnson J, Njiti VN, Lightfoot DA. Separate loci underlie resistance to root infection and leaf scorch during soybean sudden death syndrome. Theor Appl Genet 2008; 116: 967-977.

[21] Murashige T, Skoog F. A revised medium for rapid growth and bioassay with tobacco tissue culture. Physiol Plant 1962; 15: 473497.

[22] Kumari BDR, Settu A, Sujatha G. Somatic embryogenesis and plant regeneration in soybean. Indian J. Biotechnol 2006; 5: 243245.

[23] Hiraga S, Minakawa H, Takahashi K, et al. Evaluation of somatic embryogenesis from immature cotyledons of japanese soybean cultivars. Plant Biotech 2007; 24: 435-440.

[24] SoyBase - http://soybase.org/SequenceIntro.php. Retrieved on August 08, 2010. 